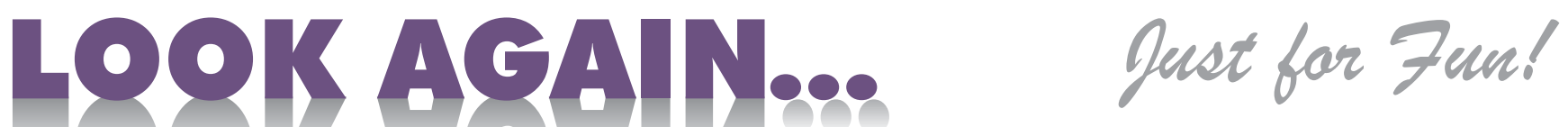

See if you can find the 8 differences

in each set of images.

\section{Superconducting city}

This optical profilometer image shows ink-jet printed micrometer-scale tracks of $\mathrm{YBa}_{2} \mathrm{Cu}_{3} \mathrm{Ox}$ superconductor. The ink used is an aqueous solution containing $\mathrm{Cu}, \mathrm{Ba}$, and $\mathrm{Y}$ ions. The "printing" is followed by a thermal treatment. The molecular structures are examples of how $\mathrm{Cu}$ ions in the ink are stabilized by triethanolamine (TEA) molecules.

Petra Lommens, Ghent University, Belgium
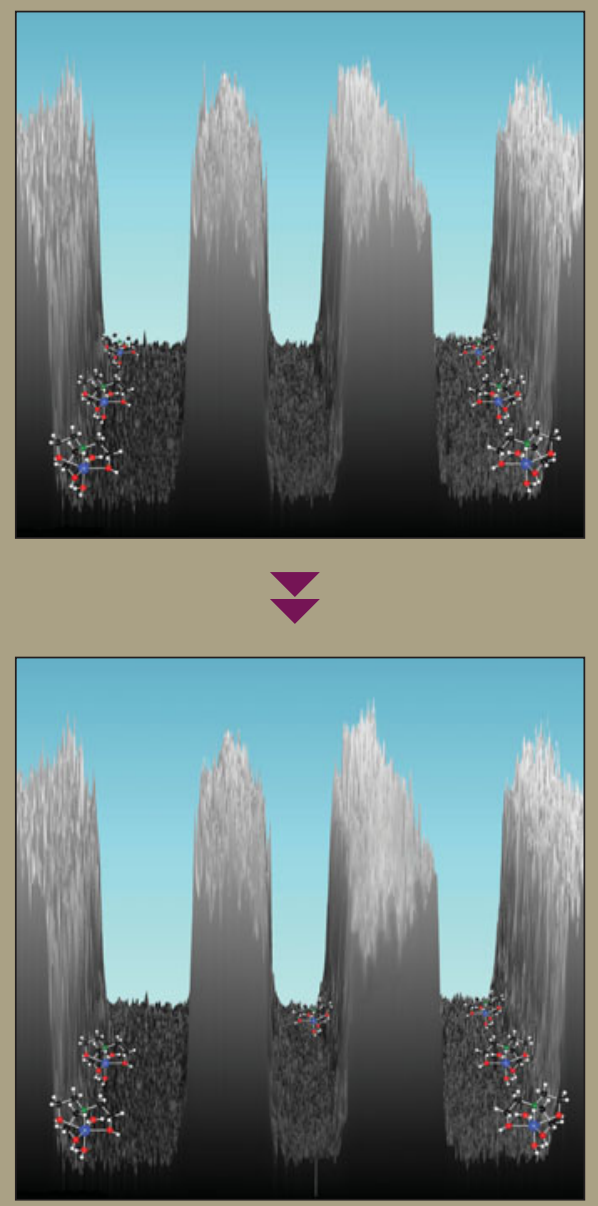

Dendritic baby giraffe

This scanning electron microscope image depicts a baby giraffe formed within a jungle of Ni-Al-C dendrites. As the molten alloy was being solidified inside a graphitic crucible, the melt was decanted, leaving behind a little dendrite wetted by a thin molten blanket. As the dendritic jungle got colder, the blanket froze and rejected carbon, which eventually crystallized as a graphite cover. Upon further cooling, the graphitic cover wrinkled, due to its thermal expansion coefficient mismatch with the metallic substrate, creating a faceted network of creases resembling the skin patches of a giraffe.

Shaahin Amini, University of California-Riverside, USA
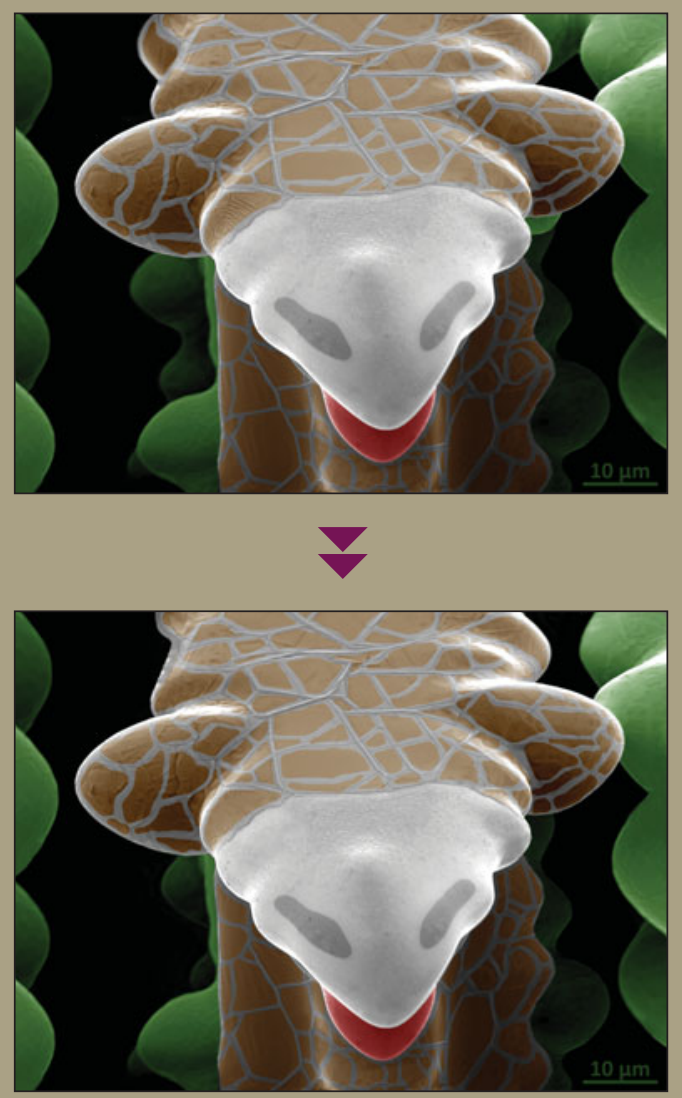

April 2013 answer key
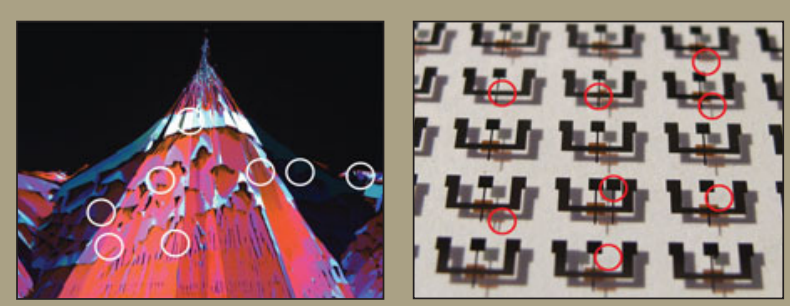

Images on the top were submitted to the Materials Research Society "Science as Art" competition.

Images on the bottom were modified in Adobe Photoshop for this "Look Again" activity. 